\title{
Effects of Product Smartness on Satisfaction: Focused on the Perceived Characteristics of Smartphones
}

\section{Won-jun Lee ${ }^{1}$ and Seungjae Shin ${ }^{2}$}

${ }^{1}$ Cheongju University, Business Administration Department, Cheongju, Korea, marketing@cju.ac.kr

${ }^{2}$ Mississippi State University, Division of Business, Meridian, MS, U.S., sshin@meridian.msstate.edu

Received 10 May 2017; received in revised form 18 September 2017; accepted 17 October 2017

\begin{abstract}
This paper investigates consumers' perceptions toward smartness characteristics of smartphones to understand the influence of product smartness on consumer satisfaction. Recent developments in information technology are accelerating the pace of change in products, particularly the emergence of smart products. Despite these technological advances, however, there is a lack of understanding about consumers who buy and use smart products. In this empirical study, five smartness dimensions of autonomy, adaptability, reactivity, multifunctionality, and ability to cooperate, are used to examine perceived product smartness which is also tested with consumer satisfaction. Based on their experiences with smartphones, 388 consumers, in their 20 s, respond to the questionnaire. Among the five factors, adaptability and multi-functionality have significant influence on perceived product smartness and consumer satisfaction. However, the other three factors do not show a significant impact. In addition, the moderator effect of customer innovativeness on satisfaction has been proven to be significant. The results of this study provide a better understanding of the impact of product smartness on customer attitudes and provide managerial implications for new product development and market management.
\end{abstract}

Keywords: Smart product, Smartphone, Product intelligence, Consumer innovativeness, Service adoption 


\section{Introduction}

The application of information technology and software is changing the nature of consumer products today. In everyday life, consumers encounter an increasing number of smart products. These products are smartphones, robotic vacuum cleaners, smart cars, smart IPTV (Internet Protocol Television)s, home network services and so on. Users' interactions with smart products provide a fascinating possibility of easing everyday work [46]. For instance, smart navigation devices can give a turn-by-turn direction for selected routes, and smart devices attached to sign posts can guide blind people in unknown environments through wireless headsets [8].

Changes in these products are inevitably affecting the attitudes and behaviors of consumers. Consumers with an experience with a smart product have a stronger purchasing motivation for smart products and have a desire to replace human intelligence and effort with that of machines [28]. However, research on smart products can mainly be found within the field of industrial engineering. The ergonomics literature addressing product smartness pays attention to the importance of user interface and design [19], [15]. In this paper, the authors try to define the theoretical concept of a smart product and understand the relationship between product smartness and consumer attitude.

This study verifies the determinants of perceived product smartness and consumer satisfaction in relation to the use of smart products. This study also applies a five-dimension model of smart products to illustrate how product smartness is constructed. This study posits that consumer innovativeness is a control variable in the relationship between perceived product smartness and consumer satisfaction. In terms of consumer attitude related to smart product, this study focuses on perception transfer from perceived product smartness to product satisfaction. The first objective of this research is to identify characteristics of smart product affecting consumer's perception and satisfaction using a smartphone as a focal product. This research also investigates the effects of consumer innovativeness in addition to the effects of perceived product smartness on customer satisfaction. In order to achieve these research objectives, this study conducts surveys on smart product users and adopts SEM (structural equation modeling) method for empirical analysis.

The key contribution of this study will be to understand the major role of product smartness in affecting consumer attitude. The authors expect the results of this study to identify critical factors that should be considered in the product planning and marketing of future products in a high technology product context such as a smartphone, home appliance, or other smart services. The rest of the paper is constructed as follows: This paper introduces interdisciplinary prior studies about product smartness and its relationship with consumers. Then, the authors present the hypotheses and research model and suggest the research methodology, followed by empirical analysis results. The paper concludes with a discussion of the research implications of its findings and further research directions.

\section{Theoretical Background}

In this chapter, we review the previous literature studies and examine the concept and characteristics of smart product to establish hypotheses.

\subsection{Concept of Smart Product}

A product with human like intelligence is commonly known as a smart product. Meyer, Framling and Holmstrom [32] describe the concept of an intelligent/smart product. They explain the difference of intelligent products from other similar concepts such as ubiquitous computing, pervasive computing, ambient intelligence, and internet of things, which focus on more connectivity and information exchange. In their study, the factors of intelligent products include reactiveness and capability of autonomous adaptation.

However, it is not easy to find a generally accepted definition of smart products in the literature [19]. The concept becomes even more confusing because some terms and concepts overlap with smart products. Wong, McFarlane, Zaharudin, and Agarwal [48] introduce the notion of the intelligent product which achieves some elements of behavior associated with an intelligent being. Other terms, such as ambient intelligence, are widely used, making the definition of a smart product difficult. Intelligent products and smart products are used interchangeably, while concepts like ubiquitous computing and ambient intelligence tend to focus on how human users interact with their environment [19], [24], [32]. Cook and Das [12] take definitions for smart environments, including pervasive computing, machine learning, and wireless and sensor networking, where all kinds of smart devices are connected for making a user's life more comfortable. Allmendinger and Lomnreglia [2] regard product smartness as the product's capability to be preemptive removing unpleasant surprises from the users' lives. Maass and Varshney [30] define smart products as products with digital representations that enable adaptation to situations and consumers to create pleasant experiences. Stander [46] defines a smart product as a physical product, software, or service, which has capabilities to communicate with other smart products and with users. Mühlhäuser [33] states that a smart product is an entity designed and made for self-organized embedding into different smart environments in the course of its lifecycle and also mentions that smart products provided improved simplicity and openness through improved interactions. He also explains the six characteristics of smart products: context-awareness, semantic self-description, proactive behavior, multimodal natural 
interface, Al (Artificial Intelligence) planning, and machine learning. Weiss, Mattem, Graml, Staake, and Fleisch [47] discover that two key challenges to realize the vision of smart products are supporting natural interaction with a user and making use of other smart products and resources available in the environment. They also insist that a product needs context information, interaction, and ubiquitous capability to be considered a smart product. To interact with the user naturally, products must have awareness of their current surroundings and context. Also, smart products must facilitate interaction for the user as much as possible. This includes automating work processes to avoid unnecessary interaction, proactively guiding the user. Ubiquitous data storing capability through WiFi or other mobile internet access technologies is needed because during a smart product's life cycle, plenty of information is required by users and data needs to be stored remotely.

\subsection{Dimensions and Characteristics}

To explain the concept of a smart product well, recent studies pay attention to the dimensions and characteristics of a smart product. Smart products possess one or more of smartness dimensions to a lesser or higher degree. In an earlier study, McFarlane, Sarma, Chiru, Wong and Ashton [31] insist that an intelligent product has several properties such as the ability to process information, visibility, communication effectiveness, and assisting decision making. They identify the Auto ID (Identification) system, which is known as RFID (Radio Frequency Identification), as a smart product. Auto ID systems can capture accurate information of products and use the captured information for manufacturing control systems.

Rijsdijk and Hultink [34]-[38] have continuously studied consumer behaviors toward smart products. In their first study on smart products, they define product smartness as consisting of seven dimensions: autonomy, adaptability, reactivity, multi-functionality, ability to cooperate, humanlike interaction, and personality [36]. They investigate the relationship between product autonomy and consumer appreciation through relative advantage, perceived complexity, and perceived risk. They find that clear impact of product autonomy on perceived risk and perceived complexity exists. In their second study [37], they explain product intelligence with six dimensions: autonomy, ability to learn, reactivity, ability to cooperate, personality, and humanlike interaction. They investigate the relationship between these six dimensions and consumer satisfaction through innovation attributes such as relative advantage, compatibility, and complexity. They find that product intelligence has a positive relationship with a relative advantage, compatibility and complexity and while relative advantage and compatibility give a positive impact on consumer satisfaction, complexity gives a negative impact on consumer satisfaction. In their recent study, Rijsdijk and Hultink [38] investigate consumer responses to new smart products with five dimensions: autonomy, adaptability, reactivity, multi-functionality and ability to cooperate. In this third experiment, smart products are divided by two groups: Group A (vacuum cleaner, lawn mower, and washing machines) with dimensions of autonomy, adaptability, reactivity and Group B (digital camera, refrigerators, and washing machines) with dimensions of multi-functionality and ability to cooperate. They find that higher levels of product smartness dimension is related to a higher level of risk, perceived relative advantage, compatibility, and complexity.

Maass and Janzen [29] characterize smart products by introducing six general dimensions: situatedness, personalization, adaptiveness, proactivity, business-awareness, and network capability. Situatedness means recognition of situational and community contexts. Personalization is defined as the tailoring of products according to consumers' needs and effects. Adaptiveness changes product behavior according to consumers' responses and tasks. Proactivity refers to the anticipation of users' plans and intentions. Business-awareness is the consideration of business and legal constraints, and network capability is the ability to communicate and bundle with other products. Mühlhäuser [33] states that simplicity and openness are the two main characteristics for a smart product. While simplicity could improve product-to-user interaction, openness would improve product-to-product interaction. His argument is that an interactive feature equipped with information technology is important for a smart product. He insists that it is useful to distinguish three knowledge classes of smart products because active knowledge of a smart product enables the product to talk, guide, propose and understand. Smart product knowledge consists of (1) knowledge about itself, (2) knowledge about its potential and actual environments, and (3) knowledge about its users. The knowledge about itself includes its features, functions, dependencies, and product history. The knowledge about environments refers to perceived possibilities to adapt to and cooperate with these environments and their constituents. The knowledge about users means the knowledge to distinguish the different user categories reflected in the life cycle of users.

Meyer et al. [32] classifies smart products based on three orthogonal dimensions: level of intelligence, location of intelligence, and aggregation level of intelligence- Table 1 summarizes a classification of intelligent products.

Stander [46] identifies a set of interaction types describing the interaction between smart products and users according to the importance of the interaction. He lists the different types of smart coffee makers' interactions [46], which include: phrase, optional predictive prompt, optional prompt, notification, predictive prompt, predictive request, request and warning. López et al. [28] also propose the I-S-A-D-N (Identify-Sensing-Actuation-Decision making-Networking) framework to explain characteristics of smart objects with various types. Each letter, coding for key features of smart objects, formulates the characteristics as follows:

- I for identity and the storage of any other relevant data 
- $\quad S$ for sensing its physical condition and its situated environment

- A for actuation of internal or external devices.

- $\quad$ D for decision making and participation in controlling other devices or systems

- $\quad \mathrm{N}$ for networking to reach and receive information through a wired or wireless network.

Table 1: Classification of intelligent product [32]

\begin{tabular}{|c|c|c|}
\hline Category & Item & Description \\
\hline \multirow{3}{*}{$\begin{array}{l}\text { Level of } \\
\text { Intelligence }\end{array}$} & $\begin{array}{l}\text { decision } \\
\text { making }\end{array}$ & to make all decisions relevant by itself without any external intervention \\
\hline & $\begin{array}{l}\text { problem } \\
\text { notification }\end{array}$ & to notify its owner when there is a problem \\
\hline & $\begin{array}{l}\text { information } \\
\text { handling }\end{array}$ & to manage its own information, given by sensors and other techniques \\
\hline \multirow{2}{*}{$\begin{array}{l}\text { Location of } \\
\text { Intelligence }\end{array}$} & $\begin{array}{l}\text { network } \\
\text { intelligence }\end{array}$ & the intelligence is completely outside the physical product at a different location \\
\hline & $\begin{array}{l}\text { intelligence } \\
\text { at object }\end{array}$ & all the intelligence takes place at the physical product itself \\
\hline \multirow{2}{*}{$\begin{array}{l}\text { Aggregation } \\
\text { Level } \\
\text { of } \\
\text { Intelligence }\end{array}$} & $\begin{array}{l}\text { intelligent } \\
\text { item }\end{array}$ & the object manages information, notifications and decisions about itself \\
\hline & $\begin{array}{l}\text { intelligent } \\
\text { container }\end{array}$ & $\begin{array}{l}\text { the intelligent container not only manages information, notifications and } \\
\text { decisions, it is also aware of the components that it may act as a proxy device } \\
\text { for them }\end{array}$ \\
\hline
\end{tabular}

They insist that various combinations of these characteristics constitute a smart product [28]. For example, a smartphone would be a $S N$-smart product because it has the ability to use multiple sensors and mobile communication technologies to connect users and other devices.

Another major study of related research has focused on the effects of smartness on customer attitudes and behavioral intentions [22], [15], [28], [38]. However, the previous research is not enough to explain the direct relationships between product smartness and customer satisfaction, and does not consider the differences between different kinds of smart products. Smart products may include significantly different applications such as systems for mobile recommendation agent, a cooking guide, a context aware in-vehicle driver information application, an intelligent washing machine, common consumer goods, or a production control system [19]. However, existing research has not been conducted on smart devices recently developed and does not reflect the changes brought about by recent technological innovations. This paper uses five smart product dimensions, which are adapted from Rijsdijk and Hultink [38] and Lee [26], as a basic research framework to analyze the smartnesss of smartphones, the latest smart technology leader.

\section{Hypothesis}

The application of IT technology and software not only changes the nature of the products, but also affects the lives of consumers. The benefits of making smart products in the company's perspective are relatively clear. Allmendinger and Lombreglia [2] report a documented growth rate in double digits for many of the companies producing smart products. In general, products are problem solutions that are transferred from providers to consumers [1]. Therefore, consumers prefer smart products to non-smart products because they believe the smarter products are better at solving their problems.

Obviously, not all products need to be smart. The benefits of a smart product depend on the context, but there are important issues to consider when deciding what products should be smart. Regarding this issue, Allmendinger and Lombreglia [2] explain the benefits of network-based smart products. They insist that when the impact of product failure is catastrophic, the value of information generated by the device is precious; the service need for the product is high; the location of the product device is too far to maintain; and the product has a positive reason to be connected and to be smart.

Even though previous theoretical studies about consumers using smart products exist, how product smartness affects consumer attitude is not clear because of the relative shortage of empirical studies. This study aims to investigate whether each dimension of a smart product affects perceived product smartness, which can lead to consumer satisfaction. To test these relationships, the authors adapt Rijsdijk and Hultink [38]'s research framework of smart product dimensions. The five dimensions of smart products are explained in Table 2. 
Table 2: Dimensions of smart product [38]

\begin{tabular}{|l|l|}
\hline Dimension & Description \\
\hline Autonomy & $\begin{array}{l}\text { the ability to operate in an independent and goal-directed way without interference of } \\
\text { the user }\end{array}$ \\
\hline Adaptability & the ability to improve the match between its functioning and its environment \\
\hline Reactivity & the ability to react to changes in its environment \\
\hline Multi-functionality & the ability to fulfill multiple functions \\
\hline $\begin{array}{l}\text { Ability to } \\
\text { Cooperate }\end{array}$ & the ability to achieve a common goal with other devices \\
\hline
\end{tabular}

Rijsdijk and Hultink [38] believe that product smartness dimensions influence innovation attributes, but they ignore the possibilities to affect consumer attitude directly. This study tries to fill the research gap by proposing hypotheses that the five dimensions influence perceived product smartness, which can finally influence users' satisfaction. In addition, the authors add consumer innovativeness as a control variable. There are seven hypotheses in this study. Hypothesis 1 through hypothesis 5 are related to the above five dimensions of smart products and perceived product smartness; hypothesis 6 is related to perceived smart products and consumer satisfaction. Hypothesis 7 is related to consumer innovativeness and its relationship between perceived smart product and consumer satisfaction. Products with selflearning capabilities are perceived as more advantageous [37]-[38]. For instance, a smart TV can gain a higher relative advantage by being able to provide a viewer with customized channel information after it analyzes and learns a viewer's channel selection behavior. Products with self-awareness may lower the total transaction costs of consumers by reducing the time necessary to procure replacements for damaged goods because the products that perceive their condition, analyze it, and attempt to change their situation if products are dissatisfied with it [8], [25]. When a consumer perceives this feature, the product will be considered smart.

\section{H1: Autonomy positively affects perceived product smartness.}

A product that is more compatible fits more closely with the consumer's way of living, resulting in higher adoption by consumers [8]. Maass and Varshney [30] insist that a smart product is learned from and adapted to other entities in a situation based on product representation. For example, Alexa, the smart voice service by Google, provides capabilities that enable customers to interact with devices with more adaptability. The more customers use Alexa, the more she adapts to speech patterns and personal preference. Smart products enrich the class of products with the capability of adaptability [30].

\section{H2: Adaptability positively affects perceived product smartness.}

Products with a higher reactivity are likely to be perceived as offering more advantage [38]. For example, an LED (Light Emitting Diode) light that turns on when someone approaches, has advantages over a non-reactive light. Also in a virtual reality system, smart objects are known to evoke more sensitive consumer responses [14].

\section{H3: Reactivity positively affects perceived product smartness.}

Mühlhäuser [33] insists that there is an increased need for smartness in using smart products as their functionalities become even more complex. Smart products make use of various modalities. Examples include microphones, speakers, touch screens, and so on. Therefore, a smart product can proactively interact with the user through multimodal interaction [41], and multi-functionality will strongly influence positive attitude of consumers [42]-[43].

\section{H4: Multi-functionality positively affects perceived product smartness.}

Allmendinger and Lombreglia [2] suggest that networking of products is able to perform seven functions making the product smart. These functions are status, diagnostics, upgrades, control and automation, profiling and behavior tracking, replenishment and commerce, location mapping and logistics. Previous research shows that the utility of a network-based product such as phones, PDA (Personal Digital Assistant)s, or fax machines, strongly depends on the number of other users that are in the same network [23], which is called network externality. Based on that, the authors expect that higher levels of ability to cooperate will be associated with higher value.

\section{H5: Ability to cooperate positively affects perceived product smartness.}

Rogers [40] asserts that an innovation which is perceived as relatively easy to understand and use is adopted faster than other products. Products that are able to communicate in a more humanlike way are expected to make consumers experience positive feelings. According to Burgoon, Bonito, Bengston, Cederberg, Lundeberg, and Allspach [10], anthropomorphic interface with animated characters and speech synthesis are very useful to users and influences user satisfaction during the users' decision-making process. Chan and Khalid [11] show that consumers evaluate products with voice control to be more fun and natural. Consumer satisfaction is described as a consumer's positive and affective evaluation of a product or service [22]. Rogers [40] insists that relative advantage of a product is a source 
of satisfaction. With the dramatic increase in the use of smart devices, it is important for smart product makers to understand the relationships between product smartness and the level of satisfaction among consumers. In the recent smartphone satisfaction studies, Shin [42]-[43] uses the Customer Satisfaction Index (CSI) and Haba, Hassan, and Dastane [20] use consumer perceived value (CPV) as variables to present a level of user satisfaction. Both studies find that quality of smart services determines customer satisfaction, which leads to usage of smart services [20]. The relationship between product performance and consumer satisfaction is well known. Spreng and Olshavsky [36] show that consumer satisfaction is caused by the perceived performance of a product. Fornell, Johnson, Anderson, Cha, and Bryant [17] find that consumer satisfaction is determined by product quality and value.

H6: Perceived product smartness positively affects consumer satisfaction.

Consumer innovativeness is known as a force that leads to innovative behaviors [39]. Rijsdijk and Hultink [37] argue that the perceived innovation attributes mediate the relationship between product intelligence and consumer satisfaction. Based on findings from an empirical study on consumer perceptions of autonomous products, they conclude that consumers evaluate products with higher levels of autonomy as more difficult to use and more likely to malfunction than products with a lower level of autonomy [36]. The level of consumer innovativeness is assumed to control the relationship between consumer satisfaction and perceived product smartness.

H7: The relationship between perceived product smartness and consumer satisfaction is moderated by consumer innovativeness.

The research model is shown in Figure 1.

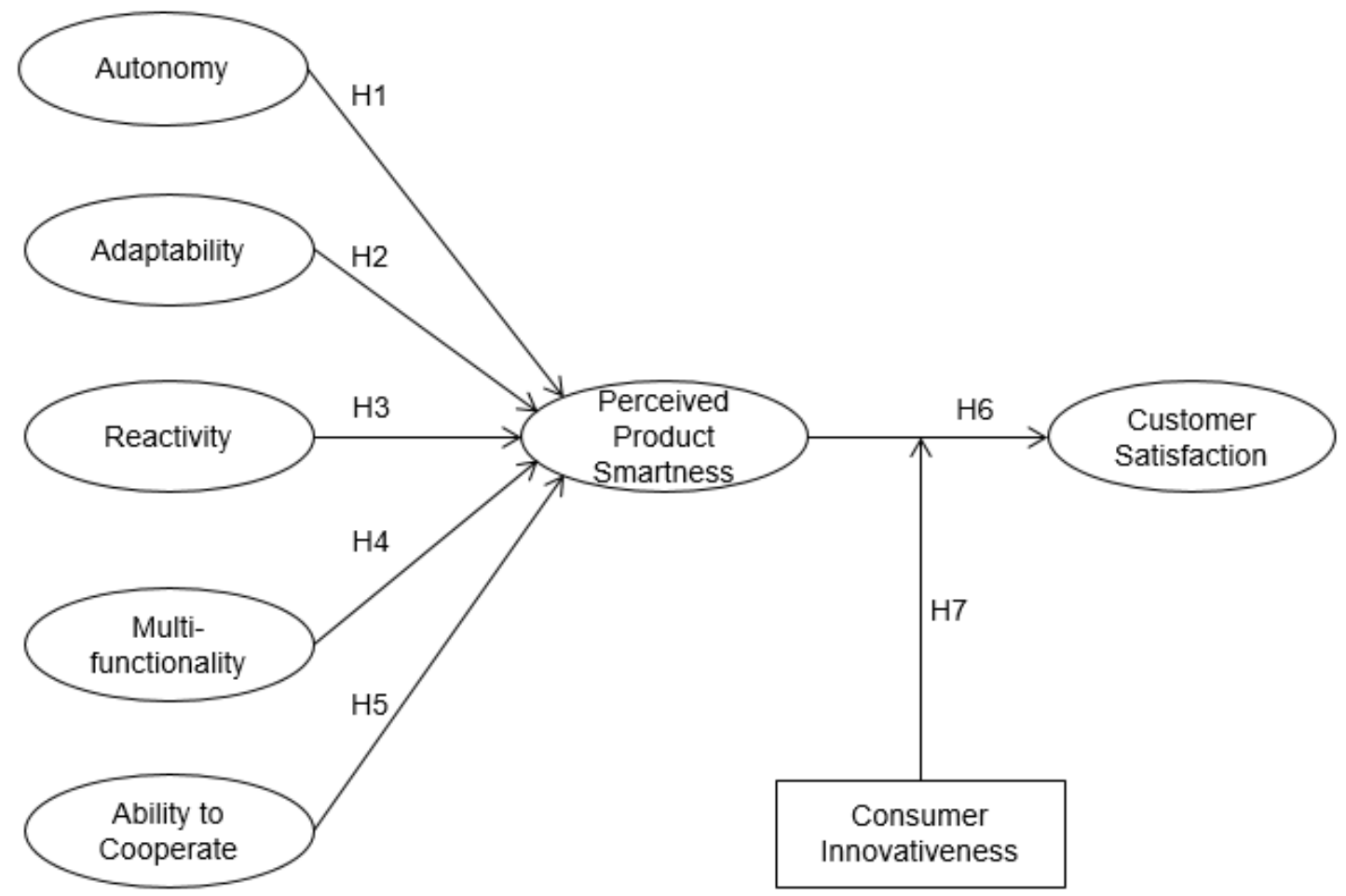

Figure 1: Research model

\section{Research Methods and Outcome}

Due to the relative scarcity of empirical research on smart products, this study's intention is to identify a smart productconsumer behavior relationship model and test it. For this purpose, causal relationships among related variables are proposed and analyzed.

\subsection{Measurement}

Measures of the constructs are developed based on several stages. In the first stage, based on the defined constructs, all measures are borrowed from the existing literatures and modified for the smartphone research context. The measurement items are modified to suit the use of smartphones. In the second stage, a list of defined constructs and 
measures is submitted to a panel of marketers and academicians to establish content validity. They are asked to rate each of these items on a 5-point Likert scale (1=strongly disagree $\sim 5=$ strongly agree) as to whether the items fit the appropriate dimensions. An example of the question is: Does this item describe the characteristics of Autonomy dimension?. According to the pre-established dropout criteria, the authors exclude items that are rated as below average of 3 points. All items must receive at least more than 3 points. This study asks respondents to read the instructions describing the background of the study before answering the questionnaire, and asks them to respond based on their experience using their smartphone. Table 3 lists the constructs and items used in this study.

Table 3: Measurement items

\begin{tabular}{|c|c|c|}
\hline Construct & Item & Source \\
\hline Autonomy & $\begin{array}{l}\text { This product goes its own way } \\
\text { This product takes the initiative } \\
\text { This product works independently } \\
\text { This product does things by itself }\end{array}$ & \multirow{5}{*}{$\begin{array}{l}{[37]-[38],} \\
{[26]}\end{array}$} \\
\hline Adaptability & $\begin{array}{l}\text { This product can learn } \\
\text { This product improve itself } \\
\text { This product acts on the basis of previously collected information } \\
\text { This product delivers a better performance over time }\end{array}$ & \\
\hline Reactivity & $\begin{array}{l}\text { This product keeps an eye on its environment } \\
\text { This product directly adapts its behavior to the environment } \\
\text { This product observes its environment }\end{array}$ & \\
\hline $\begin{array}{l}\text { Multi } \\
\text {-functionality }\end{array}$ & $\begin{array}{l}\text { This product has multiple functions } \\
\text { This product can do a lot } \\
\text { This product performs multiple tasks } \\
\text { This product fulfills multiple functional needs }\end{array}$ & \\
\hline $\begin{array}{l}\text { Ability to } \\
\text { Cooperate }\end{array}$ & $\begin{array}{l}\text { This product communicates with other devices } \\
\text { This product achieves a common goal in cooperation with other products } \\
\text { This product can be attached to other products } \\
\text { This product works better in cooperation with other products }\end{array}$ & \\
\hline $\begin{array}{l}\text { Perceived } \\
\text { Product } \\
\text { Smartness }\end{array}$ & $\begin{array}{l}\text { This product seems overall smart. } \\
\text { This product seems overall intelligent. }\end{array}$ & [39] \\
\hline $\begin{array}{l}\text { Consumer } \\
\text { Satisfaction }\end{array}$ & $\begin{array}{l}\text { I am very satisfied with the product } \\
\text { This product has many advantages } \\
\text { My experiences with the product have always been pleasant }\end{array}$ & $\begin{array}{l}{[34],[17],} \\
{[3]}\end{array}$ \\
\hline $\begin{array}{l}\text { Consumer } \\
\text { Innovativeness }\end{array}$ & $\begin{array}{l}\text { In general, I am the first in my circle of friends to know the latest product } \\
\text { I can understand how to use new product easily without other people's help }\end{array}$ & [7], [16] \\
\hline
\end{tabular}

\subsection{Sample Characteristics}

Data collection is conducted in March and April 2015. Questionnaires are collected through face-to-face interviews with Korean college students. The qualifications of these respondents are not limited to specific majors. As a result, they consist of a variety of majors, including engineering, humanities, and social sciences. Initially, a sample size of 388 is collected from colleges in the metropolitan areas, which consists of respondents who are 20 years old or older. Smartphones are selected as the focal product for this study because they may be the most well-known smart product and every respondent in this study has prior experiences with smartphones. Table 4 presents the sample characteristics. 
Table 4: Sample characteristics

\begin{tabular}{|l|l|l|}
\hline Variable & Category & Explanation \\
\hline \multirow{2}{*}{ Gender } & Male & $51.0 \%$ \\
& Female & $49.0 \%$ \\
\hline \multirow{5}{*}{ Age } & $20-21$ & $22.4 \%$ \\
& $21-22$ & $33.0 \%$ \\
& $23-24$ & $28.4 \%$ \\
\hline \multirow{5}{*}{ Smartphone brand } & $25-26$ & $13.6 \%$ \\
& above 26 & $2.6 \%$ \\
\hline & Samsung & $49.5 \%$ \\
& LG & $26.0 \%$ \\
& Apple & $17.8 \%$ \\
\hline
\end{tabular}

\subsection{Reliability and Validity}

Reliability and validity of measures are tested in two major stages: (1) general reliability analysis (GRA) and (2) confirmatory factor analysis (CFA). First, internal consistency is initially assessed by computing Cronbach's alpha score. Cronbach's alpha score is one of the most widely used measures of reliability in the marketing study. The alpha scores are found to be higher than 0.7 in every variable [34]. However, the confidence interval for the population value makes an unnecessary assumption that the multiple items have equal variance when Cronbach's alpha score is calculated [9]. Additional factor analysis is required to overcome these problems. The result is shown in Table 5.

Table 5: Reliability test

\begin{tabular}{|l|l|l|l|l|l|l|l|l|}
\hline & AUTO & ADAP & REAC & MULTI & COOP & SMAR & CS & INNO \\
\hline $\begin{array}{l}\text { Cronbach's } \\
\text { Alpha } \\
\text { (Mean) }\end{array}$ & $\begin{array}{l}.945 \\
(3.399)\end{array}$ & $\begin{array}{l}.796 \\
(3.186)\end{array}$ & $\begin{array}{l}.848 \\
(3.139)\end{array}$ & $\begin{array}{l}.938 \\
(3.967)\end{array}$ & $\begin{array}{l}.871 \\
(3.631)\end{array}$ & $\begin{array}{l}.899 \\
(3.690)\end{array}$ & $\begin{array}{l}.919 \\
(3.739)\end{array}$ & \begin{tabular}{l} 
(3.715) \\
\hline
\end{tabular} \\
\hline
\end{tabular}

CFA is performed to check both convergent validity and discriminant validity. Overall, the CFA and model fit statistics exhibit satisfactory fits. All of the construct dimensions are shown to be valid and reliable; all statistics are acceptable and there are no offending estimates. These factor analysis results specify measurement items as reflective indicators of latent constructs. Table 6 presents the results of the tests and Table 7 presents the covariance matrix of the eight dimension factors.

Table 6: Confirmatory factor analysis

\begin{tabular}{|c|c|c|c|c|}
\hline Construct & item & $\begin{array}{l}\text { Std. Estimate } \\
\left({ }^{\star} p<0.05\right)\end{array}$ & AVE & $\begin{array}{l}\text { Composite } \\
\text { Reliability }\end{array}$ \\
\hline \multirow{4}{*}{$\begin{array}{l}\text { Autonomy } \\
\text { (AUTO) }\end{array}$} & a1 & $.908^{*}$ & \multirow{4}{*}{.809} & \multirow{4}{*}{.944} \\
\hline & a2 & $.927^{\star}$ & & \\
\hline & a3 & $.881^{*}$ & & \\
\hline & a4 & $.883^{*}$ & & \\
\hline \multirow{4}{*}{$\begin{array}{l}\text { Multi-functionality } \\
\text { (MULT) }\end{array}$} & b1 & $.879^{*}$ & \multirow{4}{*}{.789} & \multirow{4}{*}{.937} \\
\hline & $\mathrm{b} 2$ & $.890^{*}$ & & \\
\hline & b3 & $.918^{*}$ & & \\
\hline & b4 & $.867^{*}$ & & \\
\hline \multicolumn{5}{|l|}{ Table 6: continuation } \\
\hline \multirow{4}{*}{$\begin{array}{l}\text { Ability to Cooperate } \\
\text { (COOP) }\end{array}$} & c1 & $.833^{*}$ & \multirow{4}{*}{.632} & \multirow{4}{*}{.872} \\
\hline & $\mathrm{c} 2$ & $.848^{*}$ & & \\
\hline & c3 & $.805^{*}$ & & \\
\hline & $\mathrm{c} 4$ & $.684^{*}$ & & \\
\hline \multirow{3}{*}{$\begin{array}{l}\text { Reactivity } \\
\text { (REAC) }\end{array}$} & d1 & $.721^{*}$ & \multirow{3}{*}{.656} & \multirow{3}{*}{.850} \\
\hline & $\mathrm{d} 2$ & $.869^{*}$ & & \\
\hline & d3 & $.834^{*}$ & & \\
\hline \multirow{4}{*}{$\begin{array}{l}\text { Adaptability } \\
\text { (ADAT) }\end{array}$} & $\mathrm{e} 1$ & $.582^{*}$ & \multirow{4}{*}{.505} & \multirow{4}{*}{.801} \\
\hline & $\mathrm{e} 2$ & $.775^{\star}$ & & \\
\hline & e3 & $.745^{\star}$ & & \\
\hline & $\mathrm{e} 4$ & $.725^{\star}$ & & \\
\hline Perceived Product & $\mathrm{f1}$ & $.956^{*}$ & .819 & .900 \\
\hline
\end{tabular}




\begin{tabular}{|c|c|c|c|c|}
\hline $\begin{array}{l}\text { Smartness } \\
\text { (SMAR) }\end{array}$ & f2 & $.852^{*}$ & & \\
\hline \multirow{3}{*}{$\begin{array}{l}\text { Consumer Satisfaction } \\
\text { (CS) }\end{array}$} & g1 & $.888^{*}$ & \multirow{3}{*}{.789} & \multirow{3}{*}{.918} \\
\hline & g2 & $.924^{*}$ & & \\
\hline & g3 & $.852^{*}$ & & \\
\hline \multirow{2}{*}{$\begin{array}{l}\text { Consumer Innovativeness } \\
\text { (INNO) }\end{array}$} & h1 & $.720^{*}$ & \multirow{2}{*}{.588} & \multirow{2}{*}{.739} \\
\hline & h2 & $.811^{*}$ & & \\
\hline
\end{tabular}

${ }^{*}$ Fit $: \mathrm{x}^{2}(\mathrm{~d} . \mathrm{f})=574.788(271), \mathrm{p}=.000, \mathrm{GFI}(\mathrm{AGFI})=.897(.867), \mathrm{CFI}=.962, \mathrm{NFI}=.930, \mathrm{SRMR}=.042, \mathrm{RMSEA}=.054$

\subsection{Hypothesis Test}

This study uses SEM methods to analyze the relations between variables. The fit statistics are satisfactory in general. The Chi-square value is $535.059(\mathrm{p}=.000)$ and not satisfactory, however, other fit statistics such as GFI (Goodness of Fit Index), NFI (Normed Fit Index), and SRMR (Standardized Root Mean Square Residual) could be more proper than a Chi-square value [3], [5]-[6]. In the test results (as shown on Table 7), all those fit statistics indicate satisfactory outcomes. Therefore, further analysis of causal relations among the variable is conducted [3].

Table 7: Covariance matrix

\begin{tabular}{|l|l|l|l|l|l|l|l|l|}
\hline & 1 & 2 & 3 & 4 & 5 & 6 & 7 & 8 \\
\hline AUTO & 1.000 & & & & & & & \\
\hline ADAP & $.644^{*}$ & 1.000 & & & & & & \\
\hline REAC & $.535^{*}$ & $.740^{*}$ & 1.000 & & & & & \\
\hline MULT & $.425^{*}$ & $.459^{*}$ & $.529^{*}$ & 1.000 & & & & \\
\hline COOP & $.378^{*}$ & $.530^{*}$ & $.556^{*}$ & $.716^{*}$ & 1.000 & & & \\
\hline SMAR & $.428^{*}$ & $.531^{*}$ & $.528^{*}$ & $.709^{*}$ & $.524^{\star}$ & 1.000 & & \\
\hline CS & $.408^{*}$ & $.531^{*}$ & $.555^{*}$ & $.728^{*}$ & $.580^{*}$ & $.854^{*}$ & 1.000 & \\
\hline INNO & $.334^{*}$ & $.441^{*}$ & $.460^{*}$ & $.661^{*}$ & $.540^{*}$ & $.575^{*}$ & $.612^{*}$ & 1.000 \\
\hline
\end{tabular}

According to the test results, hypotheses $\mathrm{H} 2, \mathrm{H} 4$, and $\mathrm{H} 6$ are significant while $\mathrm{H} 1, \mathrm{H} 3$, and $\mathrm{H} 5$ are not significant. Adaptability and multi-functionality of a smart product affects the perceived product smartness directly. Perceived product smartness influences the effect on consumer satisfaction. However, autonomy, reactivity and ability to cooperate are not significant variables.

Table 8: Hypothesis test $\left({ }^{*} p<.05\right)$

\begin{tabular}{|c|c|c|c|c|c|c|c|}
\hline \multicolumn{4}{|c|}{ Hypothesis } & Estimate (Std.) & S.E & CR & $\mathrm{p}$ \\
\hline H. 1 & AUTO & $\rightarrow$ & \multirow{5}{*}{$\begin{array}{l}\text { Perceives } \\
\text { Product } \\
\text { Smartness } \\
\text { (SMAR) }\end{array}$} & $-.005(-.004)$ & .055 & -.083 & .934 \\
\hline H.2 & ADAP & $\rightarrow$ & & $.410(.255)$ & 136 & 3.017 & $.003^{*}$ \\
\hline H. 3 & REAC & $\rightarrow$ & & $.104(.080)$ & .094 & 1.113 & .266 \\
\hline H. 4 & MULT & $\rightarrow$ & & $.680(.641)$ & .068 & 10.006 & $.000^{*}$ \\
\hline H.5 & COOP & $\rightarrow$ & & $-.089(-.079)$ & .073 & -1.208 & .227 \\
\hline H. 6 & SMAR & $\rightarrow$ & $\begin{array}{l}\text { Customer } \\
\text { Satisfaction (CS) }\end{array}$ & $.840(.882)$ & .040 & 21.172 & $.000^{*}$ \\
\hline
\end{tabular}

${ }^{*}$ Fit $: x^{2}(\mathrm{~d} . \mathrm{f})=535.059(236), \mathrm{p}=.000, \mathrm{GFI}(\mathrm{AGFI})=.895(.867), \mathrm{CFI}=.960, \mathrm{NFI}=.932, \mathrm{SRMR}=.047, \mathrm{RMSEA}=.057$

In addition, we pay attention to the mediating role of perceived product smartness and test the mediating function. The results of the mediating relationships are presented through the Model 2. The alternative model (Model 2) is identical to the research model (Model 1), except that Model 2 has direct paths from exogenous variables to customer satisfaction (CS). The results in Table 9 show that the Model 2 fits the data reasonably well. The new findings of Model 2 support the new link between adaptability (ADAP) and customer satisfaction (CS). The most powerful demonstration of mediation occurs when newly added direct paths between five exogenous variables and customer satisfaction (CS) is zero [6]. To test whether perceived product smartness (SMAR) mediates the impact of exogenous variables on customer satisfaction (CS), direct effects of exogenous variables on customer satisfaction (CS) are analyzed [3], [44][6]. According to the empirical results, the relationship between multi-functionality (MULT) and customer satisfaction (CS) is the only significant direct relationship and $x^{2}$ changes aren't satisfying enough to support the mediating relationships $\left(x^{2}(d . f)\right.$ changes $\left.=33.528(5), p>.05\right)$ [5]-[44]]. This result implies that only the partial mediating mediating relationships exist in Model 2.

In order to assess the impact of consumer innovativeness on the relationship of perceived product smartness (SMAR) 
and customer satisfaction (CS), a moderating relationship is explored. In general term, a moderator involves personal or situational variables that affect the strength of the relationships between the variables in the research model [6]. Within the framework of this research, moderator effect means that the relationships between perceived product smartness (SMAR) and customer satisfaction (CS) changes as a function of consumer innovativeness (INNO).

To test the moderator effect of consumer innovativeness, this study divides the respondents into two subgroups according to their mean scores for consumer innovativeness and performs a chi-square difference test. The moderator is a group variable and other variables are continuous variables. To test this type of dichotomy moderator, it is preferable to measure the relationships by use of the multi-group option of SEM program [3], [6]. The high innovativeness group has a stronger relationship between the perceived smartness and consumer satisfaction compared to that of the low innovativeness group (Low group=.831 < High group=.867). However, this chi-square difference test shows that there is not enough of a difference between the two groups; this is due to the change in the degree of freedom not having a significant change in the chi-square test. The result is shown in Table 9, Table 10, and Figure 2 .

Table 9: Mediation effect test $\left({ }^{*} \mathrm{p}<.05\right)$

\begin{tabular}{|c|c|c|c|c|c|c|}
\hline \multirow{2}{*}{\multicolumn{3}{|c|}{ Path }} & \multicolumn{2}{|c|}{ Model 1. Research Model } & \multicolumn{2}{|c|}{ Model 2. Alternative Model } \\
\hline & & & Estimate (Std.) & $p$ & Estimate (Std.) & $P$ \\
\hline AUTO & $\rightarrow$ & \multirow[b]{5}{*}{ CS } & & & $-.059(-.060)$ & .174 \\
\hline ADAP & $\rightarrow$ & & & & $.187(.122)$ & .082 \\
\hline REAC & $\rightarrow$ & & & & $.038(.031)$ & .600 \\
\hline MULT & $\rightarrow$ & & & & $.201(.199)$ & $.002^{*}$ \\
\hline COOP & $\rightarrow$ & & & & $.050(.047)$ & .391 \\
\hline AUTO & $\rightarrow$ & \multirow[b]{5}{*}{ SMAR } & $-.005(-.004)$ & .934 & $.007(.007)$ & .091 \\
\hline ADAP & $\rightarrow$ & & $.410(.255)$ & $.003^{*}$ & $.390(.237)$ & $.007^{*}$ \\
\hline REAC & $\rightarrow$ & & $.104(.080)$ & .266 & $.090(.068)$ & .367 \\
\hline MULT & $\rightarrow$ & & $.680(.641)$ & $.000^{*}$ & $.680(.626)$ & $.000^{*}$ \\
\hline COOP & $\rightarrow$ & & $-.089(-.079)$ & .227 & $-.104(-.091)$ & .186 \\
\hline SMAR & $\rightarrow$ & CS & $.840(.882)$ & $.000^{*}$ & $.590(.633)$ & $.000^{*}$ \\
\hline
\end{tabular}

Table 10: Moderator effect test $\left({ }^{*} p<.05\right)$

\begin{tabular}{|l|l|l|l|l|l|l|l|}
\hline Group & \multicolumn{2}{l|}{$\mathrm{H} 7$} & Estimate & S.E & CR & $\mathrm{p}$ \\
\hline $\begin{array}{l}\text { Low INNO } \\
\text { group }\end{array}$ & SMAR & $\rightarrow$ & CS & .831 & .057 & 14.668 & $.000^{*}$ \\
\hline $\begin{array}{l}\text { High INNO } \\
\text { group }\end{array}$ & SMAR & $\rightarrow$ & CS & .867 & .067 & 12.988 & $.000^{*}$ \\
\hline
\end{tabular}

${ }^{*}$ Free model $: x^{2}(d . f)=835.036(472), p=.000$, Restricted model $: x^{2}(d . f)=835.201(473), p=.000$, Difference in $x^{2}(d . f)=.165(1)$ 


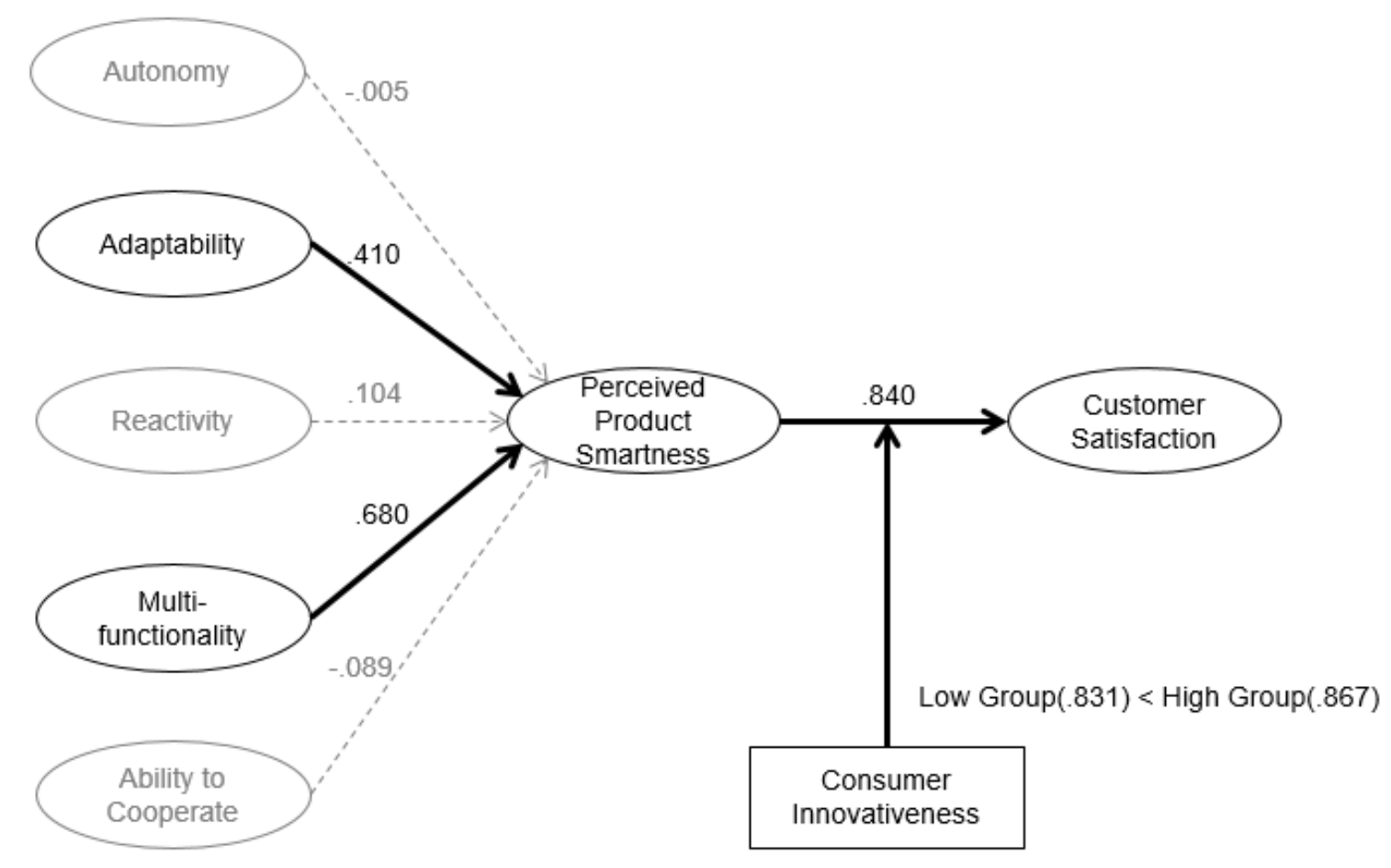

Figure 2: Test result

\section{Conclusion}

Based on our research model and empirical test results, this chapter will elaborate the conclusion of our study and propose further research issues.

\subsection{Implication and Conclusion}

This study investigates the consumer's response towards smart products, and a smartphone is used as an example of smart products that can provide consumers with intelligent functions and services. Among other smart products, smartphones are a typical catalyst that ignited the rapid adoption and use of smart technology [43].

The five dimensions of smart products (autonomy, adaptability, reactivity, multi-functionality, and ability to cooperate), are used to find an influence of perceived product smartness. In addition, we investigate the notion that the perceived smartness of a product can impact consumer satisfaction. The notable results of this study are as follows: 1) Adaptability, which is a product's ability to improve the match between its functioning and its environment, influences perceived product smartness directly. This means that adaptability can lead to consumers feeling comfortable and perceiving their products as smart. 2) Multi-functionality also significantly influences perceived product smartness. This function can make smart devices convenient because the consumers do not have to carry a variety of devices, instead they can solve many problems with an integrated smart device. As a result, versatile products with high multifunctionality are likely to be evaluated as smarter because they can be evaluated as having excellent problem solving abilities. 3) The impact of perceived product smartness on customer satisfaction is proven to be very strong, as predicted by the hypothesis. The proof of this hypothesis shows that the smarter the product is, the more attractive it is to consumers. In other words, this study confirms that the smartness of the product is a source of satisfaction to consumers and a positive attitude to the product.

However, the other three dimensional factors do not show a significant relationship. The impacts of autonomy, reactivity, and ability to cooperate are not supported. Although these five factors are proposed important factors affecting the perceived smartness of the product, the relationship may vary depending on the product type. As we mentioned in the previous section, Rijsdijk and Hultink [38] divide two groups of smart products in their third experiment, adaptability belonged to Group A (washing machine, lawn mower and vacuum cleaner) and multi-functionality belong to Group B (digital camera, refrigerator). As Gutiérrez, Garbajosa, Daiz, and Yagüe [19] mention, each smart product has different applications and characteristics, thus consumers' perception from the smart product is different.

In summary, this study differs from previous studies in that it is the first study to examine the relationship between the determinants of product smartness and satisfaction. Existing related studies consist of technology-based studies [19], 
[47], [31] and tend to overlook the impact on consumers and marketing. Although Rijsdijk and Hultink [34]-[38] attempt to understand the influence of smart products from the consumer's point of view, they ignore the effect of the smart products on market performance variables such as customer satisfaction. In their study, product smartness is only a leading predictor of product innovativeness.

This study presents several practical implications. First, the findings show that companies can improve consumer satisfaction by developing smart products that are more convenient to consumers. By enhancing adaptability and multifunctionality to existing products, companies could be selected by consumers and they could gain competitive advantage. Second, the identified control effects of consumer innovativeness also provide implications for companies' market-to-go strategies. According to the recent research by Lin, Chao, and Tang [27], some consumers continue to use traditional mobile phones despite the dramatic increase in smartphone usage. These laggard adopters did not welcome smart features and would not respond to marketing efforts for smart products. Therefore, it will be necessary to segment customers based on their innovativeness. Companies that develop smart products need to identify innovative consumer groups and target those groups first for their success in the initial market.

Third, it has been identified that product smartness may vary by product type. In past studies on consumer electronics products [34]-[37], product smartness was believed to exist in more than five dimensions. However, according to this study, adaptability and multi-functionality were the only sub-factors affecting perceived product smartness in smartphones. This implies that users may expect different kinds of product smartness depending on the product type. In other words, autonomy does not have a significant impact on perceived smartness in the case of smartphones where human-computer interaction is important, but it may have a significant effect on connected cars with high interest in autonomous driving. According to the results of this study, smartness of product may ultimately have to be defined at each product dimension.

\subsection{Limitation and Further Research}

This study has some limitations as an initial empirical study, and these limitations serve as new avenues for future research. First, one of the limitations of the study is the representativeness of the research sample. This study is limited to young consumers attending colleges in mertropolotan areas. Researchers need to study other demographic groups to understand the general power of a smart product in detail. Second, future research needs to consider the emotional effect of product smartness. For instance, emotional factors such as nostalgia could affect negatively on consumers' attitudes and intentions to use smart products [27]. Traditional users may feel a strong attachment to their old and conventional products and not adopt new technology. Third, future studies could explore whether the dimensions or components of product smartness differ by product type. In this study, only the smartphone is treated as a product of interest, and some dimensions of product smartness are not supported significantly. There is a possibility that perceived dimensions of product smartness may be changed in the case of intangible service products or B2B products.

Fourth, it may prove likely that other dimensions of the smartness need to be identified. For example, recent studies on smartphones have proposed various variables such as content quality, price conciseness, relative advantage and so on as predecessors of product smartness [43]. Fitth, The full mediation effect of perceived product smartness has not been proven and a partial mediation model has been supported. This may be due to the nature of the focal product under study or the quality of the user experience. Since product smartness is still in its infancy, lack of technical perfection may be one cause. After the technological completeness has risen, re-research will be necessary. Sixth, the research model needs to be tested in other countries with different cultural backgrounds and varying degrees of technology acceptance. For example, in countries where privacy is important, there is a possibility that product smartness may be perceived as a privacy violation. Seventh, additional research is needed to understand the impact of product smartness on overall business performance. According to the recent research of Dawid et al. [13], smart products not only provide new functionality, but also may generate new markets, new channels, and new business models. It is apparent that the market introduction of smart products will raise many academic and managerial challenges for researchers and marketers from various industries. These limitations and further research directions should be addressed in extending the proposed model in future research.

\section{References}

[1] J. W. Alba and J. W. Hutchinson, Dimensions of consumer expertise, Journal of Consumer Research, vol. 13, no. 4, pp. 411-54, 1987.

[2] G. Allmendinger and R. L. Lombreglia, Four strategies for the age of smart services, Harvard Business Review, October, pp. 1-12, 2005.

[3] J. C. Anderson and D. W. Gerbing, Structural equation modeling in practice: A review and recommended twostep approach, Psychological Bulletin, vol. 103, no. 3, pp. 411-423, 1988.

[4] E. J. Arnold and L. L. Price, River magic: extraordinary experience and the extended service encounter, Journal of Consumer Research, vol. 20, no. 1, pp. 24-45, 1993.

[5] R. Bagozzi and Y. Yi, On the evaluation of structural equation models, Journal of the Academy of Marketing Science, vol. 16, no. 1, pp. 74-94. 1988. 
[6] R. M. Baron and D. A. Kenny, The moderator-mediator variable distinction in social psychological research: Conceptual, strategic, and statistical considerations, Journal of Personality and Social Psychology, vol. 51, no. 6, pp. 1173-1182, 1986.

[7] L. A. Bettencourt, Customer voluntary performance: consumers as partners in service delivery, Journal of Retailing, vol. 73, no.3, pp. 383-406, 1997.

[8] J. Bohn, V. Coroama, M. Langheinrich, F. Mattern, and M. Rohs, Living in a world of smart everyday objects social, economic, and ethical implications, Human and Ecological Risk Assessment, vol. 10, no. 5, pp. 763-785, 2004

[9] D. G. Bonett and T. A. Wright, Cronbach's alpha reliability: internal estimation, hypothesis testing, and sample size planning, Journal of Organizational Behavior, vol. 36, no. 1, pp. 3-15, 2015.

[10] J. K. Burgoon, J. A. Bonito, B. Bengston, C. Cederberg, M. Lundeberg, and L. Allspach, Interactivity in humancomputer interaction: a study of credibility, understanding, and influence, Computers in Human Behavior, vol. 16, no. 6 , pp. 553-574, 2000.

[11] F. Y. Chan and H. M. Khalid, Is talking to an automated teller machine more natural and fun?, Ergonomics, vol. 46, no. 13-14, pp. 1386-1407, 2003.

[12] D. Cook and S. Das, Smart Environment: Technology, Protocols, \& Applications. Hoboken, NJ: Wiley, 2004.

[13] H. Dawid, R. Decker, T. Hermann, H. Jahnke, W. Klat, R. Könlg, and C. Stummer, Management science in the era of smart consumer products: Challenges and research perspectives, Central European Journal of Operations Research, vol. 25, no. 1, pp. 203-230, 2016.

[14] M. Edward, Virtual Reality System Including Viewer Responsiveness to Smart Objects, U.S. Patent Application 12/518, 618, February 5, 2013.

[15] L. R. Flynn and J. K. Eastman, Opinion leaders and opinion seekers: two new measurement scales, Journal of the Academy of Marketing Science, vol. 24, no. 2, pp. 137-147, 1996.

[16] L. R. Flynn and R. E. Goldsmith, Identifying innovators in consumer service markets, The Service Industry Journal, vol. 13, no. 3, pp. 97-109, 1993.

[17] C. Fornell, M. D. Johnson, E. W. Anderson, J. Cha, and B. E. Bryant, The American customer satisfaction index: nature, purpose, and findings, Journal of Marketing, vol. 60, no. 4, pp. 7-18, 1996

[18] A. Freudenthal and R. Mook, The evaluation of an innovative intelligent thermostat interface: Universal usability and age difference, Cognition, Technology \& Work, vol. 5, no. 1, pp. 55-66, 2003.

[19] G. Gutiérrez, J. Garbajosa, J. Daiz, and A. Yagüe, Providing a consensus definition for the term smart product, in Proceedings Engineering of Computer Based Systems (ECBS), 2013 20th IEEE International Conference and Workshops, Scottsdale, USA, 2013, pp. 203-211.

[20] H. F. Haba, Z. Hassan and O. Dastane, Factors leading to consumer perceived value of smartphones and its impact on purchase intention, Global Business and Management Research: An International Journal, vol. 9, no. 1, pp. 42-71, 2017.

[21] S. H. Han, M. H. Yun, J. Kwahk, and S. W. Hong, Usability of consumer electronic products, International Journal of Industrial Ergonomics, vol. 28, no. 3-4, pp. 143-151, 2001.

[22] C. Homburg and R. M. Stock, The link between salespeople's job satisfaction and customer satisfaction in a business-to-business context: a dyadic analysis, Journal of the Academy of Marketing Science, vol. 32, no. 2, pp. 144-158, 2004

[23] M. L. Katz and C. Shapiro, Network externalities, competition and compatibility, American Economic, Review, vol. 75, no. 3, pp. 424-440, 1985.

[24] D. Kiritsis. Closed-loop PLM for intelligent products in the era of the internet of things, Computer-aided Design, vol. 43, no. 5, pp. 479-501, 2011.

[25] J. Lee, Smart products and service systems for e-business transformation, International Journal of Technology Management, vol. 26, no. 1, pp. 45-52, 2003

[26] W-J. Lee, Can smart product make consumers satisfied?, Advanced Science and Technology Letters, vol. 47, pp. 395-398, 2014.

[27] C-Y, Lin, Y-C, Chao and T-W Tang, Why not be smarter? Examining the factors that influence the behavioral intentions of non-smartphone users, Industrial Management \& Data Systems, vol. 117, no. 1, pp. 32-49, 2017.

[28] T. S. López, D. C. Ranasinghe, B. Patkai, and D. McFarlane, Taxonomy, technology and applications of smart objects, Information System Frontiers, vol. 13, no. 2, pp. 281-300, 2011.

[29] W. Maass and S. Janzen. (June, 2007) Dynamic product interfaces: A key element for ambient shopping environments, 20th Bled e-conference, Slovenia. Domino. [Online]. Available: http://domino.fov.uni$\mathrm{mb}$. si/proceedings.nst/2007

[30] W. Maass and U, Varshney, Preface to the focus theme section: smart products, Electronic Markets, vol. 18, no. 3, pp. 211-215, 2008.

[31] D. McFarlane, S. Sarma, J. L. Chirn, C. Y. Wong, and K. Ashton, Auto ID systems and intelligent manufacturing control, Engineering Applications of Artificial Intelligence, vol. 16, no. 4, pp. 365-376, 2003.

[32] G. G. Meyer, K. Främling and J. Hőlmstrom, Intelligent product: A survey, Computers in Industry, vol. 60, no. 3, pp. 137-148, 2009.

[33] M. Mühlhäuser, Smart products: An introduction, Communications in Computer and Information Science Volume, vol. 11, no. 2, pp. 158-164, 2008.

[34] J, C, Nunally and I. H. Bernstein, The assessment of reliability, Psychometric Theory, vol. 3, no. 1, pp. 248-292, 1994

[35] C. Pechmann and S. Ratneshwar, The effects of antismoking and cigarette advertising on young adolescents perceptions of peers who smoke, Journal of Consumer Research, vol. 21, no. 2, pp. 236-251, 1994. 
[36] S. A. Rijsdijk and E. J. Hultink, Honey, Have you seen our hamster? consumer evaluations of autonomous domestic products, The Journal of Product Innovation Management, vol. 20, no. 3, pp. 204-216, 2003.

[37] S. A. Rijsdijk and E. J. Hultink, Product intelligence: Its conceptualization, measurement and impact on consumer satisfaction, Journal of the Academy of Marketing Science, vol. 35, no. 3, pp. 340-356, 2007.

[38] S. A. Rijsdijk and E. J. Hultink, How today's consumers perceived tomorrow's smart products, The Journal of Product Innovation Management, vol. 26, no. 1, pp. 24-42, 2009.

[39] G. Roehrich, Consumer innovativeness, concepts and measurements, Journal of Business Research, vol. 57, no. 6, pp. 671-677, 2004

[40] E. M. Rogers, Diffusion of Innovations (4th ed.). New York: Free, 1995.

[41] M. Sabou, J. Kantorovitch, A. Nikolov, A. Tokmakoff, X. Zhou, and E. Motta, Position paper on realizing smart products: Challenges for semantic web technologies, in Proceedings the 2nd International Workshop on Semantic Sensor Networks 2009, 26 Oct, Washington D. C., USA, pp. 135-147, 2009.

[42] D-H, Shin, Effect of the customer experience on satisfaction with smartphones: assessing smart satisfaction index with partial least squares, Telecommunications Policy, vol. 39, no. 8, pp. 627-641, 2014.

[43] D-H, Shin, Quality of experience: beyond the user experience of smart services, Total Quality Management, vol. 26, no. 8, pp. 919-932, 2015.

[44] R. A. Spreng, S. B. Mackenzie and R. W. Olshavsky, A reexamination of the determinants of consumer satisfaction, Journal of Marketing, vol. 60, no. 3, pp. 15-32, 1996.

[45] R. A. Spreng, and R. W. Olshavsky, A desires congruency model of consumer satisfaction, Journal of the Academy of Marketing Science, vol. 21, no. 3, pp. 169-178. 1993.

[46] M. Stander, Bridging the gap between users and smart products, in Proceedings Pervasive Computing and Communications Workshops, 2010 8th IEEE International Conference, Mannheim, Germany, 2010, pp. 859-860.

[47] M. Weiss, F. Mattem, T. Graml, T. Staake, and E. Fleisch, Handy feedback: Connecting smart meters with mobile phones, in Proceeding of 8th International Conference on Mobile and Ubiquitous Multimedia, Cambridge, UK, 2009.

[48] C. Y. Wong, D. McFarlane, A. H. Zaharudin, and V. Agarwal, The intelligent product driven supply chain, in Proceedings of the IEEE International Conference on Systems, Man and Cybernetics, Yasmine Hammamet, Tunisia, vol. 4, pp. 6, 2002. 